\title{
Computerising the Voting Process: On the Difficulties and Benefits of Biometric Verification Elections
}

\author{
Kofi A. Boateng and Mawulorm Akaba
}

\begin{abstract}
The use of biometric system of verification is increasingly assuming phenomenal dimensions in contemporary electoral activities across the globe. However, the academic community appears to know very little of the extent to which biometric systems of verification deal with issues of identification in the elections as well as the socio-technical matters considered vital in the computerisation of the electoral process. This paper applies a qualitative research technique by the use of a case study to make sense of difficulties and benefits in biometric elections. The paper advances the holistic idea of not only focusing on the potentials of the biometric technology but also a look beyond biometric technology to as a way of building a comprehensive picture that reflect the complexities of technological intervention in human activity system.
\end{abstract}

Index Terms-Biometric, computerisation, elections, verification.

\section{BACKGROUND}

Computerisation of human activity system has been a phenomenon that has intruded many aspects of societal life in contemporary times. It's not particularly surprising to observe this phenomenal trend, especially when viewed against the logic that people have had the occasion to predict, even if somewhat vaguely, how 'a connected set of institutional, organisational, conceptual, and technological changes will continue to extensively transform public and governance systems [1] Individuals, organisations and countries have found it vitally important to computerise activities that grant them convenience, efficiency and competitive advantage in their operations [2].

The manifestations of computerised processes include airline reservation systems, banks automatic teller machines, postage and postal tracking systems, and much recently, computerised voting system, among a host of other allied systems of electronic driven transactions. It is important to state that these computerised endeavours have largely had two fundamental purposes; to take competitive lead and also as a means of survival [3]. The computerisation frenzy appears to be gaining grounds and one such key area is 'computerised democratisation'. This can be explained as a situation in which part of the electoral process becomes heavily involved in information technology toward the

Manuscript received February 25, 2014; revised May 1, 2014.

Kofi A. Boateng is with the Department of Information Systems and Decision Sciences at the KNUST School of Business, KNUST, Ghana (e-mail: fiboat@yahoo.com, kaboateng.ksb@knust.edu.gh).

Mawulorm Akaba is with Spanish and Information and Library Studies from the University of Ghana and also with the Kwame Nkrumah University of Science and Technology, Ghana (e-mail: mawulorm@gmail.com). broader scheme of transparency and accountability in governance scheme partially driven by technological intervention.

With the coming into being of e-Society, countries are speedily and enthusiastically embracing information technologies as integral aspect of its nature. Biometric verification systems constitute part of the motivation for this current trend in systems of technology use, [2]. A growing number of both developed and developing countries have as a result - tried to incorporate biometric technologies as part of broad electoral reforms aimed at ensuring greater transparency, trust and openness in governance and democracy. Correspondingly there is a burgeoning pattern of scholarly activities focused on the application of biometric technologies in the organisation and conduct of elections across much of developed and developing world [4]. Hence the gradations of these academic efforts in biometric applications find expressions in diverse epistemological and empirical perspectives [5]-[9].

However, what appears to be missing from research efforts - which is also crucial for both the academic community and industry practice - is the extent to which computerised elections deal with issues of identity management in terms of biometric verification. Developing appreciation of biometric verification elections is crucial from, at least, two standpoints. First, the extent to which biometric systems of verification informs transparent and accountable governance. Second, the challenges inherent in, and benefits accrued to, such contemporary form of electoral projects needs to be fleshed out with the aim of broadening the frontiers of knowledge in these areas of academic research. To this end, this paper attempts to address this research question: How does biometric system of verification deal with matters of identification in elections? What are the socio-technical issues that are crucial in the computerisation of the voting process?

In an attempt to provide response to these questions the paper is structured as follows: a general account of the relevant literature is provided to highlight some of the contemporary thoughts on computerised voting and the contemporary epistemological considerations of the notions of biometric verification systems. The next session outlines the methodological issues involved in the gathering of the relevant data for presentation of the findings and subsequent analysis. A conclusion is further drawn to signpost recommendations for future research project in this area.

\section{CONTEMPORARY COMPUTERISED VOTING}

The enormous work involved in the management of elections occasions the need to apply a method that eases the 
laborious process of collecting, saving, validating and updating the data on voter identity. Again, the call from the stakeholders in elections to 'modernise' the electoral processes in the name of reforms has, to a greater degree, led to the adoption of computerised electoral processes. Contemporary voting process is regarded elsewhere as 'computerization of political communication' with an objective of encouraging broad-based decision-making occasioned by the involvement of the citizenry for more meaningful governance (Yanquing 2011). This is perceptibly feasible given the manner in which computerised systems are increasingly being accepted as legitimate method of voting. In this view, countries like Australia, Brazil, Canada, Gambia Kenya, Philippines, the United States of America, etc., apply computerised systems of technology in national elections to make decisions on the right of their leaders to govern them. It appears, almost simultaneously, that computerised voting attracted some significant attention, especially in the aftermath of the all-too popular Florida results in the 2000 American presidential polls debacle.

Given this emerging development in the application of technologies to guarantee more transparent systems of electoral accountability, it is not difficult to perceive countries' intention to use the biometric system of verification as an integral aspect of its electoral structure in recent times. It is thought that computerised voting process provides a more trusted way of choosing political party representatives and leaders as well as an effective tool in mediating the shift in political power and administration.

Computerised voting system derives its strength from a series of automated and human activities such as electronic electoral register captured through both biometric fingerprint recording devices and manual-laden name recording of the people that constitute the content of the register. The computerised nature of the process basically manifests in manual or electronic data entry, electronic verification of the electorate and electronic vote-tallying in the events leading up to the declaration of election results.

Computerised voting system comes in three fundamental forms in terms of mechanics, namely, punch card, make-sense and direct recording electronic machines [10].

It is crucial to provide some brief, if somewhat indicative, summary of these designations to underscore their relevant to computerised voting schemes. The punch cards system of voting, which has been in use for just over fifty years demand voters to indicate their ballots by punching holes in paper cards. Following this activity, the cards are then placed into a computerised counting machine. The make-sense involves the use of optical scanning technology to detect marks on each ballot, printed with ovals, circles, rectangles and squares that require voters to fill in with a pen or pencil to identify their votes. The last category, direct recording electronic machines illustrate computer terminals that make it possible for voters to administer their votes by pressing touching images on a computer screen.

There have been arguments in the literature that appear to tout the beneficial implications of computerised voting in elections. This favourable orientation to computerised voting is underpinned by such factors as accuracy, speedy and completeness while the unfavourable disposition is expressed in such matters as privacy and security breaches, data theft and inappropriate information sharing practices. Again, some scholars have also warned against computerised voting by emphasising both hardware and software difficulties in the realms of incorrect programming errors, malfunctioning of equipment, lack of accountability as well as malicious tempering. Further, there is a strong sense of pessimism in the application of computerised voting rooted in the conviction that '...there are many, many ways that there could be unexpected errors, things you couldn't even predict, and even tampering, possibly even in the writing of the program, that could alter those votes' [11]

It is the singular contention of this school of thought that whatever the nature of computerised system of voting, the issue of accountable for every cast ballot in the form of 'voter-verifiable audit trail' is crucial for reasons of transparency and trust. Anything short of this has the tendency to occasion mistrust. And this situation is better captured in the following unequivocal terms: "Unauditable voting equipment will erode confidence in our elections, causing further disillusionment of the voting public".

\section{MANAFESTATIONS AND ISSUES OF BIOMETRIC VERIFICATION SYSTEMS}

Biometric form of verification has been with humanity from as far back as the $6^{\text {th }}$ and $5^{\text {th }}$ centuries $\mathrm{BC}$, at the time when the book of Genesis was recorded [12], [13]. A typical instance of biometric system of verification, however crude, took place when Isaac attempted to identify Esau by his hairy skin, but got duped by Jacob in the process. To be sure, Anderson [14] recounts the unprecedented military application of security arrangement in which verification relied on a human trait in - again - a biblical story involving the Gileadites and the Ephraimites as found in the book of Judges 12:5-6. Indeed, societies from time immemorial have relied on certain distinct property of the humans for identifying people for whom they claim they are.

Biometric systems of technology manifest in diverse forms of applications such as the relationship between computer users and their behaviour, linking employees to their arrival and departure from the workplace, regulating user-resource routine practices as well as in online and ecommerce activities. Biometric systems are used for identification and authentication purposes. Biometric technologies allow for people to be recognized automatically by the use of distinctive personal traits such as eyes, face, hands, teeth, voice.

Biometric verification "is the process by which a claimed identity is authenticated against a previously recorded biometric template. An individual presents her/himself as being someone (e.g. 'I am Elizabeth Yap') and, in response, the biometric system seeks to answer the query: 'Is this person who s/he claims to be?' In other words, verification is the one-to-one comparison of the captured live data against the enrolled biometric template for Elizabeth Yap" [15]

The first application of biometric technology in elections took place about two and half decades ago. Modern technologies make it necessary to adopt digital means of identifying individuals with the legitimate right to participate 
in national elections in a unique way [16]. However, fingerprint biometric is more common way of establishing proof of identity during the registration and voting processes. The rationale of both of these processes is, fundamentally, to prevent the occurrence of multiple registrations and multiple voting.

Fundamentally, Schneier [17] reveals three methods by which a person could be authenticated, namely, by means of a person's cognitive content, or what the person knows, what he has and the nature of someone and by something he is. Identifying people by something they have is closely connected with biometric system that uses voiceprinting, hand geometry, retina scans, fingerprinting, handwritten signatures as well as iris, DNA profiling [17], [18].

Some benefits in the application of biometrics as a token of verification lie in the fact that it cannot be forgotten and changed, as well as its potential to uniquely identify individuals. However it is noteworthy to point out that biometrics cannot be employed as a secret, in addition to the incontrovertible fact that it can be lost as obtains in a person losing their voice. Consistent with these ups and downs of biometrics is the thought that: "No single biometric is expected to effectively meet all the requirements" [19] especially with specific reference to issues of precision, cost, privacy concerns, legal complexities and pragmatism [20].

These notwithstanding, biometrics automate the work of recognition with 'error rates of the order of $1 \%$ or probably less [21]. It is reasonable to understand that the relatively low margin of error in biometric systems encourage its sustained popularity and application in the organisation of modern elections. Accordingly, the use of biometric as a verification system is sensitive to all manner of industries. In the hospitality management for example, its use has been connected with identity assurance as a strategic approach to enhance and polish customer service practices [22].

The aviation industry is also very much known to biometric technology in its diverse forms and manifestations. Some scholars are of the view that biometric technology has established a track record of demonstrable effectiveness, convenience and time-saving

\section{METHODS}

The structure of a research design demands an organised flow of evidence that provides the researcher the distinct perspective to draw implications in respect of the basic relationships that unite the observed variables [23]. Given this viewpoint, Yin [24] emphasises the point that the quality of a case study is customarily dependent on a patterned orientation towards succinctly delineated research questions, the focus of the research and the unit of analysis. These, Yin argues, should be cautiously incorporated to create propositions derived from the data to produce findings informed by criteria for proper interpretation.

To better understand phenomena-in-context investigations against the background of certain officials in their natural, operationally distinct but electronic-laden environment and their inter-subjective inclinations, this work mainly adopts qualitative technique. Scholars share the notion that qualitative research is a more definitive research option where 'the researcher is an instrument of data collection ... analyzes them inductively, focuses on the meaning of participants...' and relate them in a comprehensible manner [25]. The decision to apply a qualitative data permits for a minimum degree of 'retrospective distortions' [26]; a situation where the researcher is unduly influenced by biases of the past.

With qualitative data, the researcher is in a favourable position to limit her prejudice in the face of openness and consequently produce a report with an unimpeachable deniability [27]. Diverse and multiple data collection methods are applied to address the delineated research issues concerning the present research. The aim is to collect informed responses from participants on the phenomena being investigated.

Case study permits the exploration of a modern phenomenon in its natural, realistic context especially 'when the boundaries between phenomenon and context are not clearly evident' and the subject under study is a 'contemporary phenomenon within some real-life context'[28]. Apparently, this kind of research lies in its power to give the researcher the opportunity to generate their own concepts from the observation at the completion of the study. Further, Walsham [29] underscores the significance of case study in an interpretive work as it offers the researcher the freehand to blend the methodological design and interpretation epistemology in such a manner as to obtain a particular socially constructed perspective. Hence it is believed that the adoption of this strategy is suitable for capturing the first-hand knowledge and experience of professionals in the field [30].

\section{Data Collection TeChNiques}

A combination of data collection techniques are employed to acquire the relevant data that guarantees the appropriate analytical discussions needed to make sense in this study given the research questions posed earlier. Fundamentally, this research combines direct observation, interviews documentary evidence and miscellaneous data to inform the subsequent interpretation of the gathered data. Each of these data collection procedure is going to be explained in turn to illustrate how they - altogether - provide the basis for the analysis of the entire research.

\section{A. Direct Observation}

The use of direct observation method allows the researcher to focus on the aspects of the research that are of particular interest to him with the least chance of being biased 'second-hand' information from the participants of the study. With this awareness, the researchers were least motivated by any intentions to interfere with the work of the informants, i.e. the electorate, electoral officers, political party agents or reps. Learning straight from the practices of the social agents allows the researchers the ability to develop insights on the various issues involved in the biometric verification process. Apart from an easy connection with the reality of the phenomenon under study, it also provides a real-life experience of the issues that arise from the whole biometric verification voting activity. The reactions of people denied 
by the technology, the anxieties demonstrated by those waiting their turn in the queue to vote, the explanations provided by electoral officers to calm tensed moments occasioned by unexpected malfunction of the biometric device. All of these required dedicating long periods of watching from the side-lines on the day of elections.

\section{B. Interviews}

With the awareness that interviews constitute an influential factor of collecting qualitative data [31], open-ended, semi-structured qualitative interview questioning techniques are used during the interviewing process. This afforded a framework that makes it possible '...to see that which is not ordinarily on view and examine that which is often looked at but seldom seen' [32]. The answers solicited from presiding officers, party agents, registered voters as well as senior election officials in different aspects of the electoral processes spawned the need for more curious questions in terms of the challenges, benefits and other pertinent issues of the voter identity verification activities. Engaging in this activity was helpful in identifying the social cues, personal opinions and beliefs and attitudes of respondents [33].

\section{Documentary Evidence}

References were also made to certain vital documents like the Electoral Commission's (EC's) training manuals, notice of poll posters, the commission's official website among others. Pieces of information assembled from these sources were crucial in making effective comparisons with the responses sought from the interviewees. Significant knowledge of the commission's management structure, its historical context, functions, etc., were also acquired. Telephone discussions and e-mail communication were used as clarification on specific issues that emerged during the write-up. All these have meant that multiple data collection methods were essential in boosting the on-site interviews, thereby enriching the research findings as a way of reinforcing validity [34]. In the final analysis, this study, consistent with the ideals of inductive studies, went through the process of iteration as data were continuously revisited to make sense of emergent issues in the course of write-up.

\section{OUR RESEARCH}

The Electoral Commission of Ghana, hereafter called the $\mathrm{EC}$, is the constitutionally mandated body to carry free and fair elections every four years in the country since the coming into effect of Ghana's 1992 republican constitution. Apart from this, the EC also undertakes and supervises all other major elections in the country, such as local administration elections, labour union elections, among others. Administratively the EC is headed by a chairman assisted by two deputies. The chairman of the EC is appointed by the president of the republic in consultation with the council of state. Legally, the position of the chairman is comparable to a court of appeal judge, which makes his tenure of office not subjected to any political whims of the party in power at any given time, until the attainment of a compulsory retirement age of 70 or as a result of mental infirmary.

By virtue of his position, the EC and all her officers are supposed to demonstrate political neutrality even though in reality he/she may have his/her bias towards a particular party in elections. Ghana's 2012 parliamentary and presidential elections brought so much at stake for, especially, the two leading political parties in the country, namely, the incumbent National Democratic Congress (NDC) and the key opposition New Patriotic Party (NPP). They are being identified here as the two leading political parties, largely because of their competitive presence in all the 275 constituencies in the country. There are six other parties that contested the presidential and parliamentary elections, namely, CPP, PPP, PNC, GCPP and two other independent candidates. The NDC and NPP campaigned vigorously, and in the process spent quite a significant amount of money on advertisements - both electronic and the traditional media radio, television and newspaper.

For the first time in the history of Ghana's democratic dispensation, biometric verification became a central issue in the elections. This is pretty understandable, given the election trajectory that the country has carved for itself. Again, biometric verification also assumed a key dimension because of the commitment of the parties involved to guarantee a commendable level of trust in the country's electoral process. The decision to reach a consensus on biometric verification was not a simple one. Initially the incumbent raised doubts against its potency in ensuring truly genuine and transparent results in the final analysis. Crucially, the electoral commission, the statutory institution legitimately charged with the conduct of elections in the country involved all the stakeholders to a common agreement on 'No Verification No Voting' (NVNV). By this no voter could cast their ballot in the elections without being biometrically verified.

\section{A. The Mechanics of Biometric Voting}

Almost all biometric voting processes worldwide follow patterns similar to voter registration prior to the main elections, voter identification and verification during the election process, voting and recording of votes cast, counting of votes and finally, the declaration of election results. The reason for Ghana's adoption of the biometric verification system, among others geared towards enhancing Ghana's electoral system, was to prevent electoral fraud which usually involves multiple voter registration and subsequently, multiple voting. Before the biometric devices were deployed on the election, there was prior piloting by the EC. And here is the view of the Director of ICT at the EC: "We have several samples of the verification machine in the office that we are going to use for piloting. The first piloting exercise will be done internally, I mean at the offices of the Electoral Commission in Accra. That exercise is slated for the first week of October. Following its success, we will then pilot it at some constituencies before the general elections".

In spite of this piloting scheme, several challenges popped up. The biometric devices were used again during the election period; which was just an aspect of the whole voting process, to help eliminate ghost names from the voters' register - 'a changeover to a new system', as Dr. Afari-Gyan puts it.

A typical scenario in the day of elections, a voter shows up in a polling centre with her voter ID. His ID is checked against a list of registered voters in that polling centre and has 
her name ticked, after which she will be asked to register her thump on the biometric device. Her portrait shows up on the biometric device to confirm her identity before a ballot is issued to her for voting. In a situation where, for some strange reasons, the biometric device fails to pick a person's identity, even with a genuine voter ID, she would not be permitted to vote. It has to be said this situation was not cast in stone; there are instances where electoral officials permitted voters to cast their ballot even when the biometric verification device has failed to recognise the finger print of such people.

\section{B. Emergent Issues in the Biometric Verification}

On the day of elections, where registered voters had to choose their members of parliament and who they wanted as their president (i.e. parliamentary and presidential polls), several biometric-related issues cropped up. Some of the biometric devices got overheated, presumably, as a result of high temperatures and would, as a result, not work. This situation, made some election officials remove the batteries and reinserted them back in those machines, and that appeared to have worsened matters, as the devices got frozen when the batteries were put back in them again. There were instances, where legitimate voters were denied the opportunity to cast their ballot because the biometric devices could not establish a link between their fingerprint and their live biometric data on the database. A deputy chairman of the EC made a remark that captures the unpredictable nature of the biometric devices:

"The Thumb-print verification has problems...it is problematic; we need to be a bit flexible...It is always better to have alternatives. If we limit it to just one, then we would have problems like the last elections," - David Kanga, the former deputy chairman of the EC.

Also, for the fact that Ghana was able to introduce a new technology, was seen as a success to some respondents. A respondent gave an interesting reason; 'at least, for the first time, Ghana tested the use of biometric system, an idea that can actually help future elections'. However, there were others who also indicated they had not entirely understood the processes involved in the biometric system. Other respondents also stated the system was not user friendly. A certain number of voters also indicated their readiness to accept the biometric verification system. One respondent remarked, 'normally, voting takes a long period of time so I was glad that the biometric system was going to be introduced to reduce voting time.'

\section{ANALYSIS}

This section of the paper presents critical appraisal of both technological and political implications of the use of the biometric device. Doing analysis of these key issues is necessary to stimulate contextual discussions at the instance of a piece of technological intervention.

\section{A. Challenges of Biometric Verified Elections}

Results from the questionnaires and interviews with some respondents revealed some difficulties encountered during the implementation of the system. Some believed the biometric system rather slowed the voting process because the verification devices could not verify some voters to enable them vote. Inadequate understanding of the biometric system also resulted in the challenges that came up during its implementation. Further, there was the breakdown of some biometric verification devices during the election exercise which was a hindrance to a smooth electoral process. However, there were some opinions of about the credibility of elections because of the involvement of the biometric devices as it was able to prevent massive occurrence of double voting which had characterised previous elections in the country. The EC officials - particularly - were of this view; and to them the biometric system, to a greater extent, ensured by the far the most successful elections ever carried out by the commission. To them, the device cut out a lot of undesirable human elements that go to a greater level of impugning the credibility of the electoral process. Double voting and voting by people without the relevant ID in the EC's view has been reduced to the barest minimum.

\section{B. Beyond Biometrics: The Political Dimension}

In the events leading up to the implementation of biometric technology in the elections, the EC was so confident and optimistic the systems capability to deal with all fraud-related activities that have the chance of marring the beauty of the elections. Here is the Director of ICT at the EC had to say. "the verification machines would be used at the various polling stations during the day of the elections to identify the voter in a clear and undisputable way, reducing to a minimum the possibility of errors, and guaranteeing the voter his or her right to express his or her vote in a democratic way".

With such almost unmistakable belief in the power of systems of technology it is feasible to understand why the EC did not consider other, possibly, human-driven alternatives in case the biometric technology did not live up to its billing.

\section{CONCLUDING OBSERVATION}

Involving biometric system of verification in a crucial election for the first time in national elections is not a simple exercise. We have not altogether downplayed the role of biometric technology in elections. However, our fundamental argument is rooted in the extent to which the implication of biometric technology raises other issues; issues that could be far more complicated than that originally considered by sponsors of such projects. It would be convincing to consider a combination of both technological and human-centred measures to handle unanticipated challenges that are occasioned by such technological interventions. Intriguing as these issues may sound, they should motivate us to question these near-conventional means of identity verification and cause us to test other possibly feasible alternatives.

\section{REFERENCES}

[1] P. Dunleavy, "Governance and state organisation in the digital era," The Oxford Handbook of Information Communication Technologies, Oxford: Oxford University Press, 2007.

[2] A. Martin and E. Whitley, "Fixing Identities? Biometric and the tensions of material practices," Media, Culture and Society, vol. 35, pp. 52-60, 2013.

[3] K. Laudon and J. Laudon, Management Information Systems. Managing the Digital Firm, Harlow: Pearson, 2014. 
[4] D. Lyon, "Biometrics, Identification and Surveillance," Bioethics, vol. 22, pp. 499-508, 2008.

[5] S. Overton, "Voter Identification," Michigan Law Review, vol. 105, pp. 631-681, 2007

[6] S. Venkatraman and I. Delpachitra, "Biometrics in Banking Security: A Case Study," Information Management and Computer Security, vol. 16, pp. 415-430, 2008.

[7] L. Egon and V. D. Broek, "Beyond Biometrics," Procedia Computer Science, vol. 1, pp. 2505-2513, 2010.

[8] L. Thomson, "Critical Issues in Identity Management - Challenges for Homeland Security," Jurimetrics J., vol. 47, pp. 335-356, 2007.

[9] K. L. Soh, W. Wongand, and K. L. Chan, "Adoption of Biometric Technology in online Applications," Interanational Journal of Business and Management Science, vol. 3, pp. 121-146, 2010.

[10] R. G. Saltman, "Issues in National Planning for the Computerization of Elections," Brasilia and Sao Paulo, 1996.

[11] D. Dill, "Computerized voting lacks paper trail, scholar warns," Stanford University, 2003.

[12] G. I. Davies, "Introduction to the Pentateuch," in Oxford Bible Commentary, J. Barton, Ed., Oxford: Oxford University Press, 1998

[13] J. Van Seters, "The Pentateuch," in The Hebrew Bible today: an introduction to critical issues, S. L. McKenzie and M. P. Graham, Eds., Louisville, Kentucky: Westminster John Knox Press, 1998.

[14] R. Anderson, Security Engineering: A Guide to Building Dependable Distributed Systems, New York: John Wiley \& Sons, Inc., 2001.

[15] J. Wayman, "Fundamentals of biometric authentication technologies," International Journal of Image and Graphics, vol. 1, pp. 93-113, 2001.

[16] S. Prabhakar, S. Pankanti, and A. K. Jain, "Biometric Recognition: Security and privacy concerns," Security \& Privacy, IEEE, vol. 1, pp. 33-42, 2003

[17] B. Schneier, Beyond Fear: Thinking Sensibly About Security in an Uncertain World, New York: Copernicus Books, 2003.

[18] A. Martin and E. Whitley, "Fixing Identity? Biometrics and Tensions of Material Practices," Media, Culture and Society, vol. 35, pp. 52-60, 2013.

[19] U. Uludag, S. Pankanti, S. Prabhakhar, and A. K. Jain, "Biometric Cryptosystems: Issues and Challenges," in Proc. the IEEE, vol. 92, pp. 948-960, 2004

[20] L. A. Jackson, "Biometric Technology: The future of assurance and authentication in the lodging industry," International Journal of Contemporary Hospitality Management, vol. 21, pp. 892-905, 2009.

[21] R. Anderson, Security Engineering: A Guide to Building Dependable Distributed System, New York: John Wiley \& Sons, Inc., 2001.

[22] J. Sweat and J. Hibbard, "Customer Disservice," Information Week, pp. 65-78, 1999.

[23] R. K. Yin, Case Study Research: Design and Methods, Third edition ed., vol. 5, Thousand Oaks: SAGE Publications, 2003.

[24] R. K. Yin, Case Study Research: Design and Methods, Thousand Oaks, California: SAGE Publications Ltd, 2014
[25] J. W. Creswell, Qualitative Inquiry and Research Design: Choosing among Five Traditions, Thousand Oaks, California: Sage Publications, Inc., 1998.

[26] M. B. Miles, "Qualitative Data as an Attractive Nuisance: The Problem of Analysis," Administrative Science Quarterly, vol. 24, pp. 590-601, 1979.

[27] L. M. Smith, "An evolving logic of participant observation, educational ethnography, and other case studies," in Review of Research in Education, L. Shulman, Ed., Chicago: Peacock Press, 1978.

[28] R. K. Yin, "The Case Study Crises: Some Answers," Administrative Science Quarterly, vol. 26, 1981.

[29] G. Walsham, "Interpretive Case Studies in IS Research: Nature and Method," European Journal of Information Systems, vol. 4, pp. 74-83, 1995.

[30] I. Benbasat, D. Goldstein, and M. Mead, "The Case Research Strategy in Studies of Information Systems," MIS Quarterly, vol. 11, pp. 368-386, 1987

[31] M. D. Myers and M. Newman, "The qualitative interview in IS research: Examining the craft," Information and Organization, vol. 17, pp. 2-26, 2007.

[32] H. J. Rubin and I. S. Rubin, Qualitative interviewing: The art of hearing data, Second edition, Thousand Oaks, CA: Sage, 2005.

[33] J. E. Kendall and K. E. Kendall, "Metaphors and Methodologies: Living Beyond the Systems Machine," MIS Quarterly, vol. 17, pp. 37-47, 1993

[34] R. Stake, The Art of Case Study Research, Thousand Oaks, CA: Sage, 1995.

Kofi Agyenim Boateng is a lecturer in the Department of Information Systems and Decision Sciences at the KNUST School of Business, KNUST, Ghana. He holds B.A.(Hons) publishing studies from KNUST. However, his M.Sc. in analysis, design and management of information systems and Ph.D in information systems were all obtained from the London School of economics and political science in 2005 and 2010 respectively.

Since 2005, he has been connected with both academic and professional institutions in varied capacities as lecturer, visiting lecturer, researcher and reviewer. His current research undertaking includes the following: ICT mediated interaction and control, e-government, ubiquitous computing and SMEs, trust and communication technologies, biometric technology, computerisation and automation of work.

Mawulorm Akaba holds a bachelor's degree in Spanish and information and library studies from the University of Ghana and MBA with emphasis on management information systems at the Kwame Nkrumah University of Science and Technology. Her research interests include e-government, business process re-engineering, IT in healthcare, system automation. 